\title{
“Escrever com a luz" as migrações humanas: Sebastião Salgado, entre estética e ética ${ }^{1}$
}

\section{Ana Paula Coutinho \\ Universidade do Porto - ILCML}

Resumo: 0 álbum Êxodos, publicado em 2000 por Sebastião Salgado, resultante das suas múltiplas incursões fotográficas ao longo de mais de seis anos, consubstancia todo um projecto em torno de algumas das migrações em massa que redesenharam a carta demográfica do mundo, na passagem do século XX para o século XXI. Através de uma leitura que convoca a análise do discurso fotográfico e do(s) discurso(s) narrativo(s) implícitos em Êxodos, bem como a sua articulação com outros meios de difusão e de intervenção social da arte, próprios à era da sua reproductibilidade e mercantilização, procuro mostrar por que o trabalho fotográfico de Sebastião Salgado se tornou simultaneamente famoso e controverso, trazendo para isso à colação algumas questões de cariz estético e ético, suscitadas por este processo de representação e exposição dos "desterrados".

Palavras-chave: Sebastião Salgado; Êxodos; projecto fotográfico; chiaroscuro; estética/ética

Résumé: L'album Exodes, publié en 2000 par le photographe Sebastião Salgado, est le résultat des voyages qu'il a effectués, exprès et au long de plus de six ans, pour un projet autour des migrations de masse qui ont redessiné la carte démographique du monde, au passage du XXe au XXIe siècle A travers une lecture qui appelle à l'analyse du discours photographie et du (des) discours narratif(s) sousjacents à Exodes, aussi bien qu'à son articulation à d'autres moyens de diffusion et d'intervention sociale de l'art, propres à l'ère de sa reproductibilité et de sa marchandise, je cherche à montrer les raisons pour lesquelles le travail photographique de Sebastião Salgado est devenu à la fois fameux et controverse. A cet effet, seront ici convoquées quelques questions d'ordre aussi bien esthétique qu'éthique que ce processus de 
représentation (et d'exposition) des « déracinés» n'arrête pas de suciter-

Mots-clé: Sebastião Salgado, Exodes, projet photographique, chiaroscuro, esthétique-éthique

$A$ photo is a small voice, at best, but sometimes - just sometimes - one photograph or a group of them can lure our senses into awareness. Much depends upon the viewer; in some, photographs can summon enough emotion to be a catalyst to thought.

W. Eugene Smith

Apesar de ser um modo de registo do instante, a imagem da interrupção de um continuum no tempo e no espaço, a fotografia conta com uma história já longa de parceria com a experiência de continuidade que representa a "viagem", entendida aqui numa aceção vasta de "deslocação" humana, independentemente dos motivos, percursos e meios de locomoção implicados. Para essa estreita relação contribuíram decisivamente fotógrafosviajantes ou viajantes-fotógrafos como Fritz Henle (1909-1993), Édouard Boubat (19231999), Henri-Cartier Bresson (1908-2004), Marianne Breslalauer (1909-2001) ou Annemarie Schwarzenbach (1908-1942). A reputação de cada um deles no universo fotográfico ficou, senão exclusiva, pelo menos indelevelmente ligada à fotografia de viagem, ou seja, àquela captura mecânica, através de fenómenos físico-quimicos, da paisagem física e humana que cada um levou a cabo em terras mais ou menos longínquas e desconhecidas, pelo menos para aqueles que eram, e nalguns casos continuam a ser, os potenciais observadores ou recetores dessas imagens.

$\mathrm{Na}$ atual era digital, em virtude do enorme boom na prática fotográfica com recurso aos mais diversos aparelhos, meios e plataformas de divulgação, a associação entre fotografia e viagem (e, em particular, turismo) aumentou exponencialmente e tem 
contribuído, ainda que de modo indirecto, para a redefinição da fotografia. Aquela "arte média" que Pierre Bourdieu, há mais de 40 anos, se dedicou a escalpelizar do ponto de vista sociológico, tem em muito contribuído para o alargamento das representações visuais do mundo, com resultados que além de manifestarem uma grande evolução e inovação tecnológica neste domínio, concorrem para a banalização do ato fotográfico, quando não para um efeito anestesiante das imagens.

É todavia inegável que, para muitos artistas contemporâneos, a deslocação não só condiciona como tem estado no cerne configurativo das respetivas obras (Davila 2002). Pensemos, como mero exemplo, naquele que sempre se auto-intitulou como "viajantemigrador" - Bernard Plossu, fotógrafo francês que, nos anos 60, à margem das grandes tendências da fotografia e designadamente da fotografia comercial, desenvolveu um trabalho plástico com a fotografia, tanto em diálogo com a poesia, como em estreita ligação à vida e à condição de um indivíduo em deslocação.

Já num outro campo da relação entre fotografia e viagem, se não mesmo no polo oposto do largo espectro abrangido por aquilo a que se pode chamar fotografia, ${ }^{2}$ destaca-se o fotojornalismo, mais ou menos dependente ou complementar da atividade jornalística, e cuja história também está muito ligada a deslocações, desde logo, por aquelas exigidas pela reportagem de guerras ou de outras catástrofes e circunstâncias-limite, em que acabaram por se notabilizar grandes fotógrafos como Robert Capa (1913-1954) ou Rolf Gillhausen (1922-2004). O próprio autor do álbum Exxodos (Salgado, 2000) sobre o qual aqui me concentro, é considerado um dos mais importantes fotojornalistas da atualidade. Na verdade, embora os projetos de Sebastião Salgado há muito tenham extravasado do jornalismo, a sua carreira como fotógrafo partiu exatamente do chamado "fotojornalismo humanista", aquele que representava o vector comum à maior parte dos fotógrafos reunidos em torno da Agência Magnum, uma cooperativa fotográfica criada no pós-guerra, em 1947, com o objetivo de assegurar uma maior autonomia aos fotógrafos, ao mesmo tempo que cuidava da divulgação do seu trabalho em diferentes órgãos da imprensa, assegurando-lhes os respetivos direitos de autor.

Nascido no Brasil, mas radicado em França desde 1969, economista de formação, 
mas dedicado exclusivamente à fotografia a partir da década de 70, Sebastião Salgado foi membro de Agências como a Sygma e a Gamma, embora seja a referida Magnum aquela a que esteve ligado mais tempo, até fundar, em 1994, com a sua mulher, Lélia Wanick Salgado, uma Agência exclusivamente destinada à produção e divulgação do seu próprio trabalho fotográfico - Amazonas images. ${ }^{3}$ o projeto de estreia dessa Agência foi justamente aquele que Sebastião Salgado desenvolveu em torno da "humanidade em trânsito" e que o levou a fazer inúmeras viagens de ida e regresso, entre 1993 e 1999, em mais de quarenta países e em quatro continentes. Não era de todo a primeira vez que Sebastião Salgado se dedicava durante vários anos a um projeto fotográfico determinado, concebido como um verdadeiro "ensaio fotográfico", à imagem do que também foram fazendo outros fotógrafos e membros da Magnum, tais como David Seymour (1911-1956), Philip Jones Griffiths (1936-2008), Martine Franck (1938-2012) ou Josef Koudelka (1938). Enquanto "ensaios", os trabalhos destes fotógrafos pressupõem e desencadeiam pensamento crítico sobre uma determinada realidade ou problemática social. No caso em análise, Sebastião Salgado já vinha a desenvolver, desde finais dos anos 80 (Salgado 1986), uma reflexão visual sobre o "estado do mundo", de que é exemplo a longa reportagem que, entre 1986 e 1993, dedicou ao «trabalho» e que o levou a fotografar milhares de trabalhadores na (ainda) era industrial (Salgado 1996). Terá aliás sido no decurso desse projeto que, nas palavras de Lélia W. Salgado, o fotógrafo começou a ficar particularmente sensível às inúmeras movimentações em massa de pessoas no mundo inteiro, cada vez mais pressionadas por conjunturas económicas e políticas extremamente graves e violentas. 0 projeto fotográfico que então abraçou com o propósito de vir a apresentá-lo em exposição e em livro na viragem do século (depois de algumas publicações parcelares em revistas internacionais), viria a tornar-se numa simultânea síntese e antevisão da "era das migrações e dos refugiados". Trata-se de uma realidade demográfica, social e política que extravasou do último século e milénio e tem vindo a tornar-se num fenómeno cada vez mais vasto e complexo, para o qual se têm aliás virado, ainda que por vagas, todos os holofotes mediáticos e as mais variadas plataformas de discussão.

No texto introdutório a Exxodos, o próprio Sebastião Salgado não ilude que o facto de 
tanto ele como Leila terem sido sucessivamente migrantes e exilados, e continuarem a ser, numa palavra, "deslocados" na Europa, possa ter contribuído para se sentirem particularmente empenhados e identificados com esse projeto da "humanidade em trânsito" (Salgado 2000: 9). No entanto, como já atrás ficou assinalado, trata-se de uma ideia que surge na continuidade dos seus trabalhos anteriores, onde já ressaltavam quer a opção de fotografar indivíduos e situações ligados a países ou regiões periféricas, quer as consequências demográficas dos grandes desequilíbrios económicos e sociais no mundo.

Para se compreender o trabalho de Sebastião Salgado, há que entender, por um lado, que a câmara, para este fotógrafo, funciona como um microfone direcionado àqueles que não costumam ter acesso à palavra, pelo que seu trabalho baseia-se no cruzamento deliberado de uma determinada estética e de um propósito de «ativismo», não tanto numa linha de confronto político aberto, mas mais de «subtil persuasão» (Borge 2012: X). Por outro lado, há também que ter em conta que os processos de produção e de difusão dos seus projetos fotográficos (como aliás da generalidade dos fotógrafos contemporâneos) fazem com que não estejamos apenas perante uma imagem fotográfica considerada fenomenológica e individualmente, mas diante da inserção da fotografia na chamada "indústria cultural"4. Daqui resulta que se torna impossível, ou pelo menos inadequado, fazer um estudo meramente semiológico das imagens produzidas pela câmara de Sebastião Salgado, ou, dito de outro modo, seria redutor pretender ver e julgar as suas fotografias como se fossem imagens isoladas e fruto do acaso, esquecendo que se enquadram num projecto determinado que implica quer uma narrativa, quer vários meios de difusão: exposições, imprensa periódica, livros, palestras, além de outros objetos culturais e até, por vezes, alguns programas educativos específicos. Trata-se por isso de uma estética pro-ética, radicada num vasto dispositivo de formas e protocolos que não se limitam apenas (e o que já não seria pouco) ao número de opções em jogo no instante da captura de imagem: ângulo, lente, distância focal, abertura, velocidade, ISO....

Concentrando-nos então no álbum Êxodos, 5 facilmente se depreende que, embora ele tenha como arquétipo narrativo o segundo livro do Antigo Testamento que conta a história da libertação dos filhos de Israel da escravidão no Egito, Sebastião Salgado opta por 
um plural - êxodos - que, além de ecoar as correspondentes palavras latina e grega, aponta de imediato para a diversidade de situações retratadas, desde a fuga de milhares de ruandeses ao genocídio perpetrado no seu país nos anos 90 , à imigração vietnamita, aos refugiados afegãos, ao desterro dos palestinianos no Líbano, ao êxodo rural na América latina ou ao movimento dos Sem Terra no Brasil, entre muitas outras situações de migração e exílio.

Dividido em quatro partes que apontam para deslocações mais ou menos forçadas e longas nos diferentes continentes, o álbum está organizado de acordo com os seguintes intitulados:

I. Migrantes e refugiados: o instinto de sobrevivência (apresentando situações envolvendo as Travessias entre o México e os EUA e do Estreito de Gibraltar, os boat people no Vietname, os afegãos deslocados, as fugas em massa dos curdos, dos palestinianos ou ainda dos ex-jugoslavos);

II. A Tragédia Africana: um continente à deriva (com fotografias do Sudão, do Ruanda, de refugiados angolanos ou da repatriação de moçambicanos no final da guerra civil);

III. A América Latina: o êxodo rural, desordem urbana (focando os índios da Amazónia brasileira, o abandono de campos no Equador ou as comunidades zapatistas no México);

IV. Ásia: a nova face urbana do mundo (onde sobressaem imagens da luta pela sobrevivência nas Filipinas, das Honduras, depois da passagem de um furacão, das minorias no Vietnam ou das megalópoles asiáticas).

Se no Livro do Exxodo acompanhamos a narrativa de uma deslocação coletiva marcada por sucessivas provações, também no álbum Êxodos existem imagens de várias deslocações, com uma narrativa por fragmentos (legendas) que acompanha a travessia do fotógrafo de uma ponta a outra do globo. No entanto, ao contrário da narrativa bíblica, onde o êxodo se integra no projeto divino de salvação do povo eleito, não existe no álbum de Sebastião Salgado qualquer determinação teleológica ou qualquer forma de libertação. Mesmo que exista um fio condutor do princípio ao fim, isto é, uma linha implícita a unir as 
inúmeras imagens de indivíduos desalojados, despojados e em trânsito, à última parte dedicada àquele que representa por excelência o lugar de instalação e permanência - a cidade - "a nova face urbana”, não há como reconhecer que todas essas imagens da IV e última partes do álbum estão indelevelmente marcadas pelos sinais contraditórios da opulência e do desequilíbrio, da desproporção entre a dimensão humana e o império urbano da matéria. Do ponto de vista da construção da narrativa visual, note-se que o álbum abre com uma fotografia de migrantes clandestinos a tentarem ultrapassar a linha divisória entre a América Central e a América do Norte, no rio Suchiate, antes de entrarem nos comboios de carga na Ciudad Hidalgo (México), 6 e acaba com uma fotografia panorâmica que mostra um grupo de indivíduos a praticar Tai-chi ao nascer do sol em Xangai. ${ }^{7}$ Num primeiro momento, poder-se-ia pensar que finalizar o álbum com essa imagem era indiciar que a humanidade em trânsito tinha chegado a uma espécie de porto seguro, que estaríamos perante a imagem do reequilíbrio do homem instalado na «polis», já não de um desterrado... Contudo, essa leitura, digamos otimista, pressuporia fechar os olhos, digamos literalmente, àquilo que a fotografia representa: as figuras humanas ficam manifestamente reduzidas, inferiorizadas, diante de um horizonte de edifícios mastodônticos em contraluz e que a respetiva legenda identifica como sendo "o moderno distrito financeiro de Pudong, com a torre da TV Pérola do Oriente ao fundo e o Grand Hyatt Hotel, com os seus 94 andares à direita". Ao invés de um plano aproximado das pessoas, a escolha de uma fotografia panorâmica, num plano em picado, oferece uma perspetiva bem mais simbólica do grande desequilíbrio entre a realidade humana e a realidade arquitetónica numa megalópole ${ }^{8}$. Esse efeito de sugestividade crítica, distópica, torna-se ainda mais incisivo quando se atenta na legenda de Sebastião Salgado. São palavras finais que, além de darem conta dos efeitos do tempo, concluem com aquilo que, antes, parecia inimaginável: “(...) em apenas uma década a cidade mudou ao ponto de ficar irreconhecível. Ela representa hoje a face capitalista da China Comunista, 1998” (Salgado, 2000:31).

A representação das megacidades e do capitalismo selvagem está portanto longe de significar qualquer libertação da servidão dos lugares de partida dos mais diversos migrantes e, feito o cômputo geral, Sebastião Salgado sai deste longo périplo como um 
viajante profundamente desiludido: "Em todo o lugar, impera o instinto individual de sobrevivência. Mesmo assim, como espécie, parecemos propensos à autodestruição" (Salgado 2000:15).

Apresentada a moldura global da enunciação em Êxodos, as imagens de partida e de chegada da arqui-viagem do fotógrafo a acompanhar as múltiplas deslocações que o álbum abrange, impõe-se realçar outros aspetos deste projeto fotográfico, fazendo-o sob o signo do chiaroscuro. Não é por acaso que escolho este termo que designa, como se sabe, uma técnica pictórica à base do jogo de luzes e sombras, criando um efeito de tridimensionalidade nos objetos representados. Trata-se de transpor para a estética fotográfica de Sebastião Salgado essa associação, a um tempo íntima e dramática, de luz e sombra das fotografias (sempre a preto e branco), ao mesmo tempo que, a um outro nível, se aponta, para a inextricabilidade de algumas questões de carácter estético e ético, umas mais claras e evidentes, outras mais obscuras ou discutíveis, tanto a montante como a jusante do acto de disparar o obturador da câmara.

Ora, se há um aspeto muito claro no trabalho de Sebastião Salgado é a sua intencionalidade social. Mesmo que o autor, em jeito de balanço de todo um projeto de vida, pareça subestimá-lo ou mesmo negá-lo ao declarar que "A fotografia não é um activismo, não é uma profissão» (Salgado 2013: 144) e que fotografar para si não tem a ver com «decisões racionais» (ibidem), a verdade é que, em muitos outros momentos, foi expondo que as suas fotografias fazem parte de um projeto não apenas determinado - por analogia, dir-se-ia existir aqui uma espécie de "photographie à thèse" - como ainda articulado com outras formas de intervenção ou consciencialização social. ${ }^{9}$ No caso concreto de $\hat{E} x o d o s$, o fotógrafo partiu para o terreno já com a ideia da perspectiva que pretendia dar das deslocações forçadas no mundo contemporâneo, tal como viria a explicar(-se) depois, na «autobiografia» que resulta de longas conversas com a jornalista Isabelle Francq, e à qual foi dado o título Da minha Terra à Terra:

Ao entrar no IIIํ milénio, quis retratar estas pessoas desalojadas e louvar a sua vontade de inserção, a sua coragem face ao desenraizamento, a sua incrível capacidade de adaptação em situações frequentemente muito difíceis. Queria mostrar que, à sua maneira, todas trazem ao mundo o seu 
empreendedorismo e a riqueza das suas diferenças. No início do século XXI, tentei mostrar a necessidade de reconstituir a família humana com base na solidariedade e na partilha. (Salgado 2014: $76)^{10}$

Importa referir, no entanto, que essa longa experiência com "desterrados" acabaria por levá-lo a questionar-se sobre aquelas que eram, à partida, as suas certezas ou convicções políticas (Salgado 2000: 7-8), pelo que se, por um lado, as fotografias continuaram a ter em conta alguns dos propósitos iniciais, como seja, apresentar situações diversas, por vezes inesperadas, sinais paradoxais de um mundo de deslocados e em deslocação, por outro, a sua crença na diversidade e evolução da humanidade ficou profundamente abalada. A narrativa implícita a Êxodos está, por conseguinte, longe daquela imagem pré-idealizada de "família humana com base na solidariedade e na partilha", acima citada.

Também é por demais evidente que, apesar de estarmos perante uma fotografia documental de cariz social, com reputados antecedentes, como Lewis Wickes Hine, nos inícios do século $\mathrm{XX}$, ou como Dorothea Lange, que aliás também ficou especialmente conhecida pelas suas fotografias com trabalhadores migrantes na década de 30 (vd. o seu conjunto de retratos de Florence Owens Thompson, 1936), isso não exclui de modo nenhum o empenho técnico na sua composição, bem assim como a busca de uma certa harmonia estética capaz de criar empatia no observador de cada uma das imagens, independentemente dos referentes em causa.

Assim, como qualquer narrativa fotográfica, este projeto de Sebastião Salgado pressupõe algumas técnicas de gestão da atenção e do olhar, que se integram numa perceção dinâmica, sequencial e temporalmente estendida da imagem, ${ }^{11}$ além de convocar também referências culturais, designadamente bíblicas e pictóricas. É neste sentido que o autor de Terra tem sido visto como um sucessor da esteticização deliberada do fotojornalista americano Eugene Smith, que ficou particularmente conhecido pelas suas fotografias da Segunda Guerra Mundial, ou por reportagens nos anos 50, como Nurse Midwife Spanish Village Smoky City (Pittsburgh), e que foi também um reputado membro da agência Magnum. ${ }^{12}$ 
Tal como Eugene Smith, Sebastião Salgado tem praticado o método da imersão para a realização dos seus projectos (ainda que para a composição fotográfica opte, por vezes, pela perspetiva de uma testemunha estrategicamente distante), e em geral prefere também a profundidade emocional à profundidade de campo, optando por aproximar os "alvos" da imagem através de grandes planos.

A sua preocupação pela estética da imagem é por conseguinte visível na escolha dos enquadramentos das fotografias, um enquadramento claramente subjetivo que busca o envolvimento emocional - um pathos -, não apenas aquele que está associado aos acontecimentos em si, mas também aquele que resulta do modo da sua representação. Por isso mesmo, diante de situações trágicas ou perante um ambiente globalmente disfórico como aquele que atravessa todos estes êxodos, deparamos com algumas imagens de registo declaradamente lírico, como aquela onde pequenos vultos se perdem na paisagem, como se estivéssemos perante uma delicada composição pictórica, ${ }^{13}$ ou outra onde se vislumbra um grupo de miúdos assustados, e simplesmente iluminados pelos raios de luz à entrada de uma gruta, ${ }^{14}$ e/ou ainda aquela que regista um cenário aparentemente pacífico de uma aula ao ar livre. 15 Neste último caso, o nosso olhar que é conduzido por um plano ligeiramente contra-picado seguindo as raízes de uma árvore, quase fica apaziguado pela harmonia da imagem, ignorando aquilo que a legenda virá depois denunciar. ${ }^{16}$ Do mesmo modo, a fotografia de uma criança perdida, sozinha, num campo deserto, de costas para um comboio desfocado ao fundo ${ }^{17}$ provoca-nos a sensação paradoxal de uma composição perfeita, num cenário implicitamente trágico, cujos contornos efectivos só a legenda permite entender, limitando assim o poder de impressão e projeção da própria imagem. Trata-se, na realidade, de refugiados da guerra dos Balcãs, perdidos num campo da Croácia Oriental, para quem a composição ferroviária, simbólica e dramaticamente parada, é o único e possível abrigo, numa viagem forçada de que não conhecem o final. Poderia evocar aqui muitos mais exemplos, como as fotografias panorâmicas de paisagens naturais no Equador,18 ou como a marcha ao amanhecer de uma longa fila de indivíduos a caminhar num cenário granulado de névoa, quase onírico ${ }^{19}$. Perante a beleza dessas imagens, que não é naturalmente alheia ao "habitus" do próprio fotógrafo, o observador facilmente esquecerá, ou poderá mesmo 
ignorar, caso não chegue a ler as legendas impressas num fascículo à parte, o contexto histórico e social em que as imagens foram capturadas. A beleza, nestes casos, torna-se paradoxal e obscena - acusam alguns - uma vez que se trata de imagens que parecem lutar contra a degradação humana ao mesmo tempo que criam beleza em torno dela (Cláudio 2008: 58-59); ao chamarem a atenção sobre elas próprias, desviam o nosso olhar daquilo que era suposto testemunharem e denunciarem São, em suma, imagens que, no mínimo, desestabilizam qualquer estudo sociológico ou antropológico sobre as migrações, por revelam pontos de luz e/ou de sombra que, por norma, são inapreensíveis em estatísticas, categorias, nomenclaturas ou relatórios.

A reputada ensaísta Susan Sontag foi uma das vozes mais críticas desta tendência para a "fotografia da consciência" de Sebastião Salgado, e outras vozes têm-no também acusado de pretender ser uma espécie de teólogo da libertação com uma câmara na mão. A autora de Olhando o Sofrimento dos Outros (2003), embora já não se mostrasse tão segura de algumas das teses que havia defendido nos seus ensaios sobre fotografia dos anos 70 , nomeadamente no que diz respeito à diminuição de efeito de algumas fotografias de atrocidades (2003: 110) ou no que se refere à presença de uma dimensão espetacular em certo tipo de tipo de fotografia ${ }^{20}$, foi particularmente implacável ao apelidar o trabalho de Sebastião Salgado de "retórica beata do género 'A Família do Homem”" (idem: 84). Por outro lado, aproveitaria também para considerar injustas, ou pelo menos pouco rigorosas, aquelas críticas que se apoia(va)m nas alegadas ligações das fotografias de Sebastião Salgado ao fetichismo mercantilista, ou a determinadas circunstâncias ligadas à sua exibição. Para a autora de Olhando o Sofrimento dos Outros, o problema não residia tanto nessas questões contextuais, mas nas fotografias "propriamente ditas" e, em particular, no facto de os fracos ficarem reduzidos, por assim dizer, à sua fraqueza em trabalhos fotográficos onde não são devidamente nomeados: "Um retrato que recusa nomear o seu sujeito torna-se cúmplice, ainda que inadvertidamente, do culto da celebridade que alimentou um apetite insaciável pela sorte oposta da fotografia: reservar um nome apenas aos famosos reduz o resto a instâncias representativas das respetivas ocupações, etnias, condições" (idem: 86). 
À falha pelo anonimato infligido pelo fotógrafo aos diferentes migrantes, refugiados e exilados, mostrados em Exxodos, a ensaísta americana acrescentava ainda a lacuna e o perigo da generalização indiferenciadora. Se para o fotógrafo, o mais marcante desta sua experiência de imersão em torno das mais variadas situações de deslocação forçada, fora exatamente ter-se apercebido das similitudes que marcam os mais distantes cenários no mundo (Salgado 2000: 15), já para Sontag, a representação fotográfica dessa "vaga homogeneidade" significa um foco de desmobilização da atenção, diminuindo assim a capacidade de intervenção dos observadores: "Com um tema concebido a tal escala escrevia ela - a compaixão apenas pode vacilar - e ficar abstracta. Mas toda a política, como toda a história, é concreta" (Sontag 2003: 85-86).

Assim, se para uns, a fotografia de Sebastião Salgado fraqueja na sua independência por causa do manifesto ativismo dos direitos humanos do seu autor; para outros, trata-se de uma estética fotográfica que precisamente falha o alvo político que deveria visar, quando se deixa conduzir pela generalização ou pela emoção estética. 0 próprio Sebastião Salgado tem, entretanto, procurado defender-se de algumas dessas críticas, realçando que, sem querer propriamente dar lições de moral ou tranquilizar consciências (Salgado 2013: 92), o seu trabalho procura mudar mentalidades (Singer 2010: 42-43); promover a discussão para a qual deve também contribuir o envolvimento emocional tanto do fotógrafo como do(s) observador(es); mostrar que os mais pobres possuem dignidade e "buscam, de forma criativa, uma vida melhor" (apud Claúdio 2010: 73) e, finalmente, incentivar a justiça social, uma vez que são os migrantes mais desfavorecidos quem mais têm sofrido as consequências das fronteiras reais e simbólicas impostas pela globalização.

"O sal da terra" - uma metáfora de inspiração bíblica, mas que pode evocar também os sais de prata da fotografia analógica -, é o título do mais recente filme documentário sobre a vida e obra de Sebastião Salgado21, e revela-se de facto como síntese eficaz e simbólica do propósito que foi estruturando a vida e a obra deste fotógrafo. Para Parvati Nair, autora de A Different light. The Photograph of Sebastião Salgado, importa ter em conta que as imagens deste autor proporcionam ao observador a oportunidade de dar uma 
resposta ética à imagem (Nair 2011: 46), pelo que as suas fotografias não são apenas sobre aquilo que mostram, mas são também sobre aquilo que sugerem e projetam (idem: 118). ${ }^{22}$

No entanto, importa também ter em conta que apesar de Sebastião Salgado estar profundamente convicto de que a "espécie humana é uma só" (2000: 15) e de que "Há diferenças de cor, de idioma, de cultura e de oportunidades, mas os sentimentos e as reações das pessoas se parecem muito" (ibidem), a verdade é que as suas fotografias não chegam a todas elas e, regra geral, são até desfrutadas por quem nunca passou por qualquer situação migratória ou de êxodo. Se isto não retira a virtualidade de consciencialização das imagens, reduz-lhes certamente o raio de ação, ao mesmo tempo que delas exclui, ainda que inconsciente ou involuntariamente, a leitura e projeção pessoal daqueles que, depois de terem sido objeto da fotografia, poderiam (ou deveriam) ser também seus observadores. Só se esses indivíduos pudessem ter acesso a estas representações dos seus destinos exílicos é que o projecto fotográfico não continuaria a plasmar a relação de força que implicitamente questiona: uns que partem, fogem, erram perdidos, sofrem todo o género de desequilíbrios, e outros que observam a uma distância de segurança e de algum deleite... Quero com isto dizer que, até certo ponto, o observador das fotografias de Sebastião Salgado encontra-se no mesmo lugar distanciado, ou na posição eticamente discutível e até, porventura, censurável de "voyeur", a partir da qual Sebastião Salgado fotografou, respetivamente, refugiados ruandeses a caminho do Burundi23 e migrantes numa patera à deriva no Mediterrâneo. ${ }^{24}$ Todavia, poderá também contra-argumentar-se dizendo que dificilmente Salgado poderia fotografar de outra maneira, ou que se não o tivesse feito como fez, talvez as suas imagens não tivessem tanta projeção; talvez não se soubesse de algumas realidades trágicas, rigorosamente contemporâneas, mas ignoradas ou subestimadas nos círculos onde precisamente as suas fotografias tendem a circular. No caso concreto talvez não se tivesse começado a prestar atenção ao fenómeno migratório ou às consequências de uma revolução industrial em fase de declínio. 0 facto de as suas fotografias circularem apenas, ou antes de mais, entre os mais afortunados do mundo, ultrapassa em grande medida responsabilidade do próprio autor, pois tem a ver com modos e regras de funcionamento no campo artístico ou nos diferentes circuitos socioculturais. Em todo o caso, Exodos desencadeou um 
programa educacional no Brasil (Salgado 2000a), o que não pode deixar de ser visto como um programa deliberado de inclusão e abertura a mais públicos, não apenas para a fotografia em si, mas também e sobretudo para as ações de intervenção e de solidariedade com todo o tipo de migrantes.

Poder-se-ia continuar com este exercício de argumentação e de contraargumentação, com evocação de pontos de luz e pontos obscuros; parece-me, contudo, impossível separar completamente aquilo que é (ou é visto como) "luz" daquilo que fica ensombrado na estética pro-ética da fotografia de Sebastião Salgado. Parece-me, entretanto, fundamental referir também que a intencionalidade própria a este tipo de trabalho fotográfico implica um determinado tipo de disponibilidade por parte de quem vê, sob pena de as suas fotografias se tornarem duplamente insignificantes, mesmo se porventura muito apreciadas e de elevado valor comercial.

Assim, se é verdade que estamos perante uma estética fotográfica que pressupõe e/ou desencadeia todo um vasto dispositivo de suportes de difusão para dar resposta a modos complementares de intervenção e de comercialização ${ }^{25}$, também não deixa de ser oportuno lembrar o risco para que apontava Theodor Adorno, não só na sua Teoria Estética, mas também nos seus fragmentos em Minima Moralia. Penso, muito em especial, naquele que o filósofo dedica à chamada "indústria cultural", sob o título ou lema de "Serviço ao cliente", onde chama a atenção para o facto de produtos dessa "indústria" em vez de serem um estímulo, serem antes "um modelo para as formas de reagir a um estímulo inexistente" (Adorno 2001: 207).

Fieis ao inesgotável propósito crítico da modernidade, teremos assim de continuar a perguntar: Até que ponto as fotografias de Sebastião Salgado têm resistido às leis da "indústria cultural" inserida nos mecanismos tentaculares próprios a uma economia global? Esse enquadramento geral, a montante e a jusante do acto de fotografar, constituirá apenas um "desvio" obscuro para quem se propõe "escrever com a luz"? Talvez não saibamos as respostas definitivas para estas perguntas, mas sabemos que reside aqui a questão de fundo estético e ético, o maior labirinto da contemporaneidade, aquele onde todos nós vagueamos, fotógrafos e observadores, autores e recetores, numa jornada mais ou menos 
longa, e em que cada um representa ao mesmo tempo Teseu e Minotauro, em busca de um lugar a que chamar uma câmara, tão só, clara. Ou então, casa do mundo.

\section{Bibliografia}

Adorno, Th. W. (2001), Minima Moralia, Lisboa, Edições 70 [1951].

Benovsky, Jiri (2010), Qu'est-ce qu'une photographie?, coll. «Chemins Philosophiques », Paris, Vrin.

Bogre, Michelle (2012), Photography as activism: images for social change, New York and London, Focal Press.

Bourdieu, Pierre (1989), Un art moyen. Essai sur les usages sociaux de la photographie, Paris, Minuit [1965].

Cheng, Katherine (2006), Beyond Looking: Sebastião Salgado's Religious Response to a World in Crisis . [ Disponível em http://hdl.handle.net/10066/768]

Cláudio, Ana Luíza de Abreu (2008), "Êxodos” e a migrações contemporâneas: um estudo sobre o discurso fotográfico de Sebastião Salgado, Universidade Federal Rural do Rio de Janeiro.

Davila, Thierry (2002), Marcher, créer. Déplacements, flâneries. Dérives dans l'art de la fin du XXème siècle, Paris, Éditions du Regard. 
Mora, Gille/ Hill, John T. (1998), W. Eugene Smith. The Camera as Conscience, Thones Hudson Ld.

Nair, Parvati (2011), A Different light. The Photograph of Sebastião Salgado, Durham and London, Duke University Press.

Salgado, Sebastião (1986), Sahel: L'Homme en Détresse, France, Prisma Presse and Centre National de la Photographie, For Médecins Sans Frontières.

-- (1996), Trabalho. Uma Arqueologia da Era Industrial, Lisboa, Caminho.

-- (2000), Exxodos, Concepção e Design de Lélia Wanick Salgado, Lisboa, Caminho.

-- (2000a), Deslocamentos populacionais e novas formas de solidariedade/fotografias de Sebastião Salgado, textos de Zilda Márcia Gricoli Iokoi, São Paulo, BEI Comunicação (Coleção Êxodos; programa educacional).

-- (2014), Da Minha Terra à Terra [com Isabelle Francq], Lisboa, Individual.

Singer, Andrey (2010), Sebastião Salgado, behind the lens, Contexts, vol. 9, n. $3:$ 40-45.

Sontag, Susan (2003), Olhando o Sofrimento dos Outros, trad. de José Lima, Lisboa, Gótica.

-- (2012), Ensaios sobre Fotografia, Tradução de José Afonso Furtado, Lisboa, Quetzal [1977].

Wenders, Wim/ Salgado, Juliano Ribeiro (2014), o Sal da Terra. Uma Viagem com Sebastião Salgado, Decia Filmes - Amazonas Images - DVD, Midas Filmes - 2015. 
Ana Paula Coutinho é Professora associada do Departamento de Estudos Portugueses e Românicos da Faculdade de Letras da Universidade do Porto, onde tem lecionado sobretudo nas áreas da Literatura Comparada e dos Estudos Franceses. Doutorada em Literatura Comparada (1998) e com Agregação em Literaturas e Culturas Românicas (2010), sempre se dedicou à literatura contemporânea numa perspectiva comparatista, tendo nos últimos anos desenvolvido particular investigação no domínio das interculturalidades e das representações literárias e artísticas das migrações e do exílio. Integrou vários anos a Direcção do Instituto de Literatura Comparada (2001-2003; 20122015; 2015...) e é actualmente a sua Coordenadora Científica. Coordena igualmente a base digital Ulyssei@s. Membro colaborador do CRIMIC (Université Paris IV), colabora ainda com o Programa Non-Lieux de l'Exil (Collège d'Études Mondiales - FMSH). É vice-presidente da Alliance Française do Porto. Tem vários artigos publicados em revistas e outras publicações colectivas, nacionais e estrangeiras (Colóquio/Letras, Cadernos de Literatura Comparada, Revue de Littérature Comparée,Diogène,Gávea-Brown, Carnets, Latitudes: Cahiers Lusophones,Intercâmbio...). Dos livros publicados ou editados, destacam-se António Ramos Rosa. Mediação Crítica e Criação Poética (Quasi Edições, 2003. Prémio Ensaio PenClub); Lentes Bifocais - Representações literárias da Diáspora Portuguesa (Afrontamento, 2009), Passages et Naufrages migrants. Les fictions du détroit (com Maria de Fátima Outeirinho e José Domingues de Almeida), Paris, L'Harmattan, 2012; Nos \& leurs Afriques. Images identitaires et regards croisés Constructions littéraires fictionnelles des identités africaines cinquante ans après les décolonisations (com Maria de Fátima Outeirinho e José Domingues de Almeida) Frankfurt, Berlin, Peter Lang, 2013; Marguerite Duras. Palavras $e$ Imagens da Insistência, ILCML, Colecção Libretos, 2015. 
ANEXO

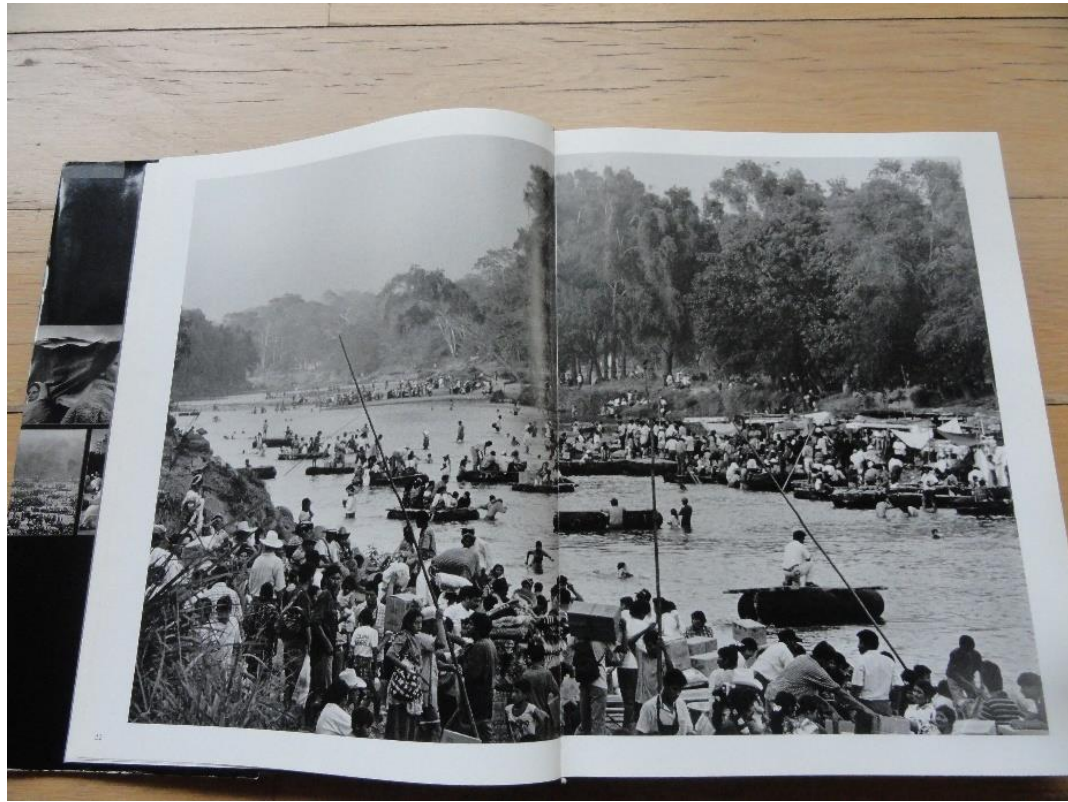

Imagem 1

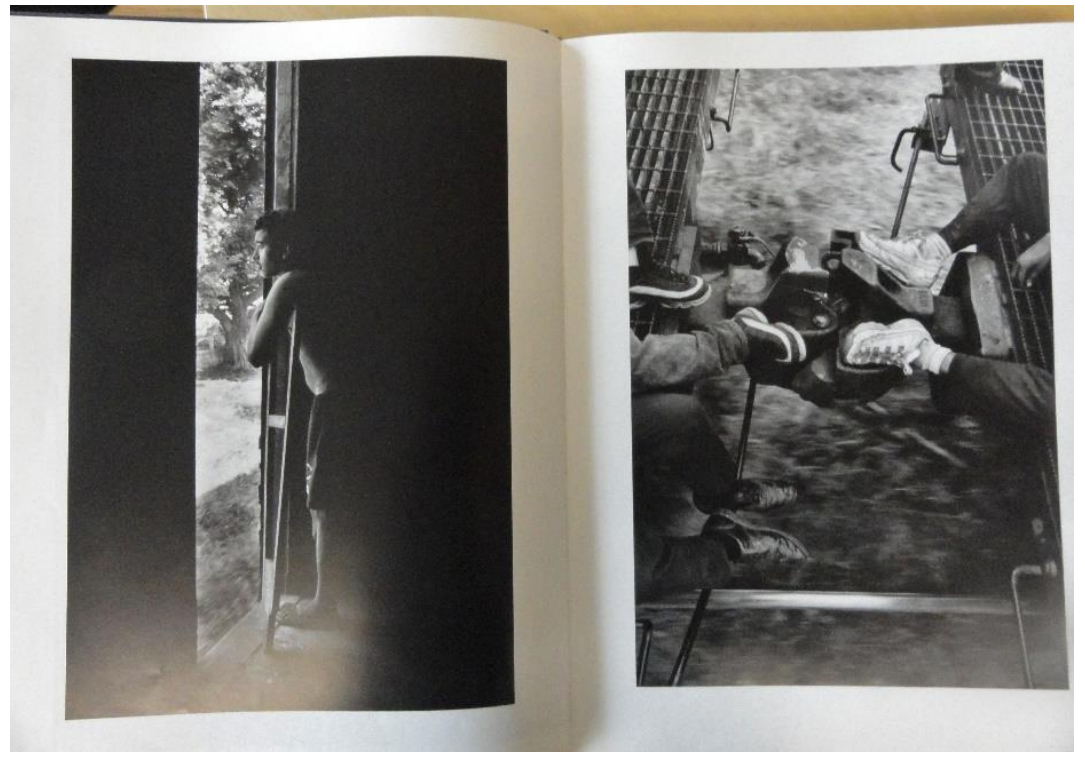

Imagem 2 
"Escrever com a luz" as migrações humanas: Sebastião Salgado, entre estética e ética

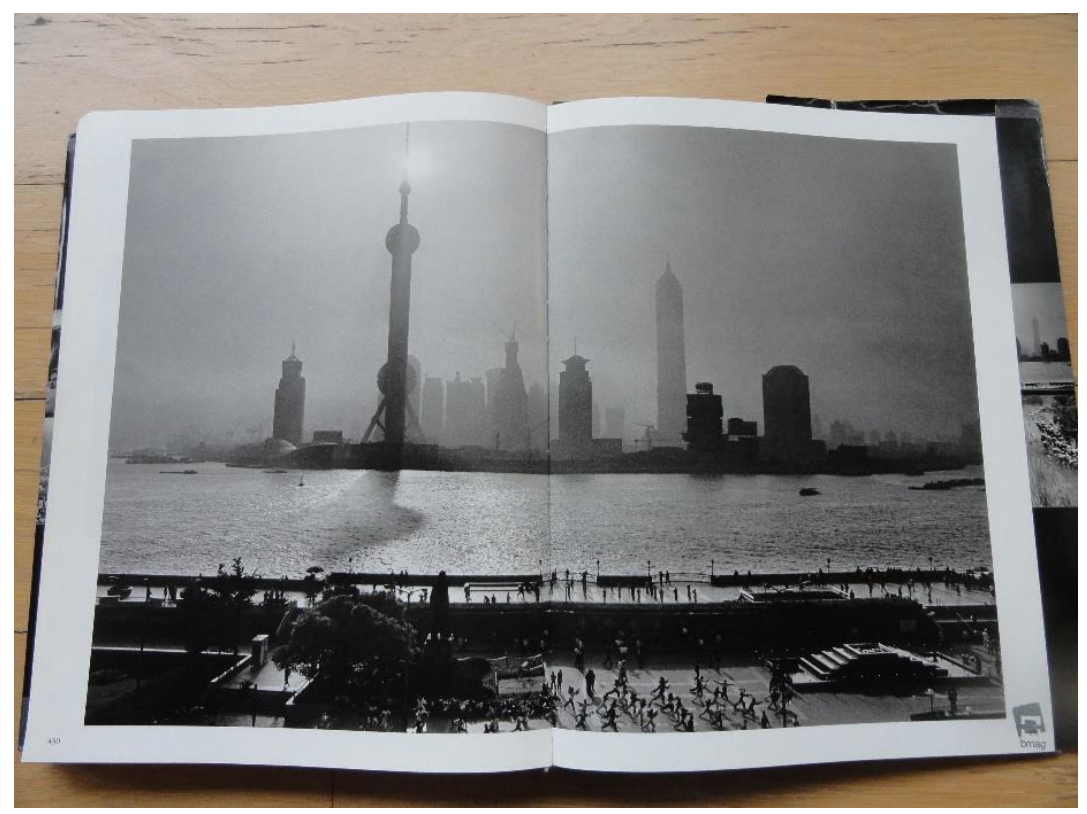

Imagem 3

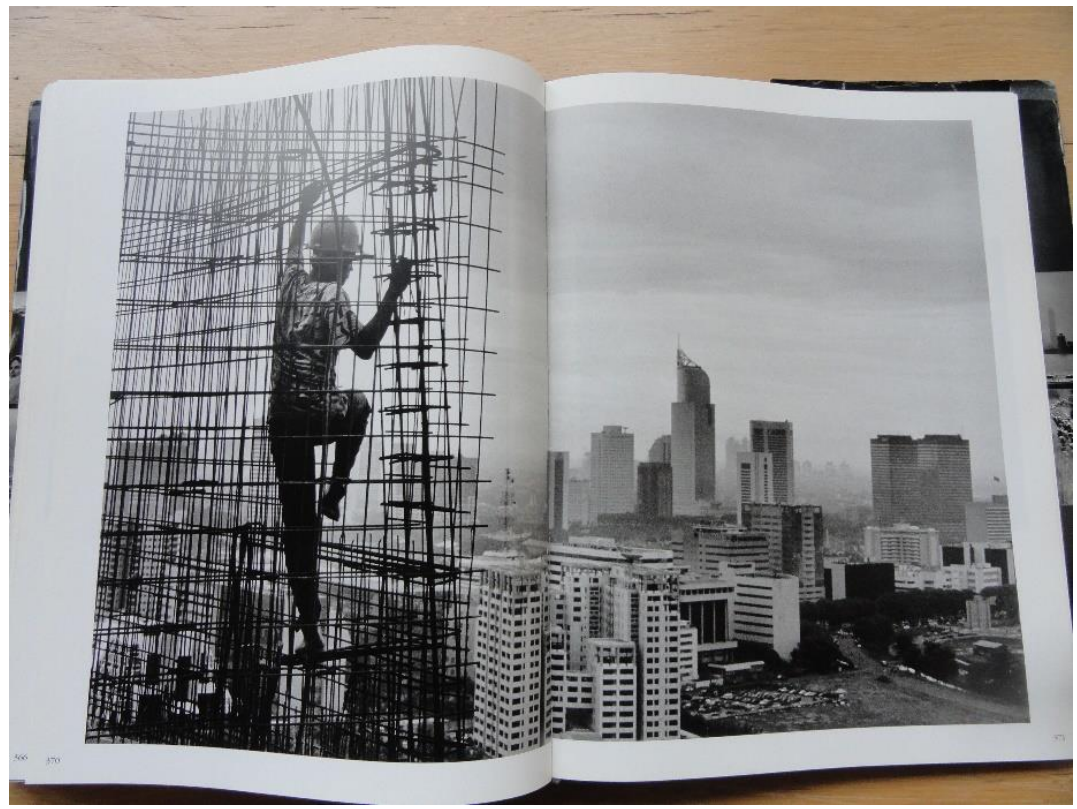

Imagem 4 
Ana Paula Coutinho

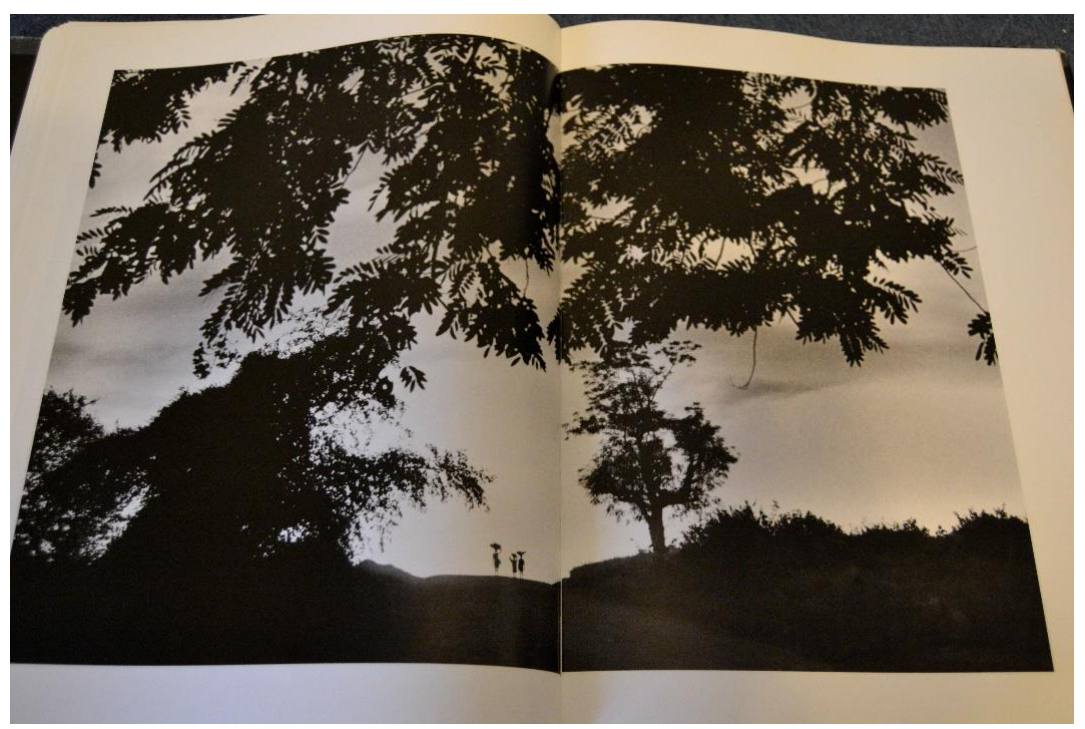

Imagem 5

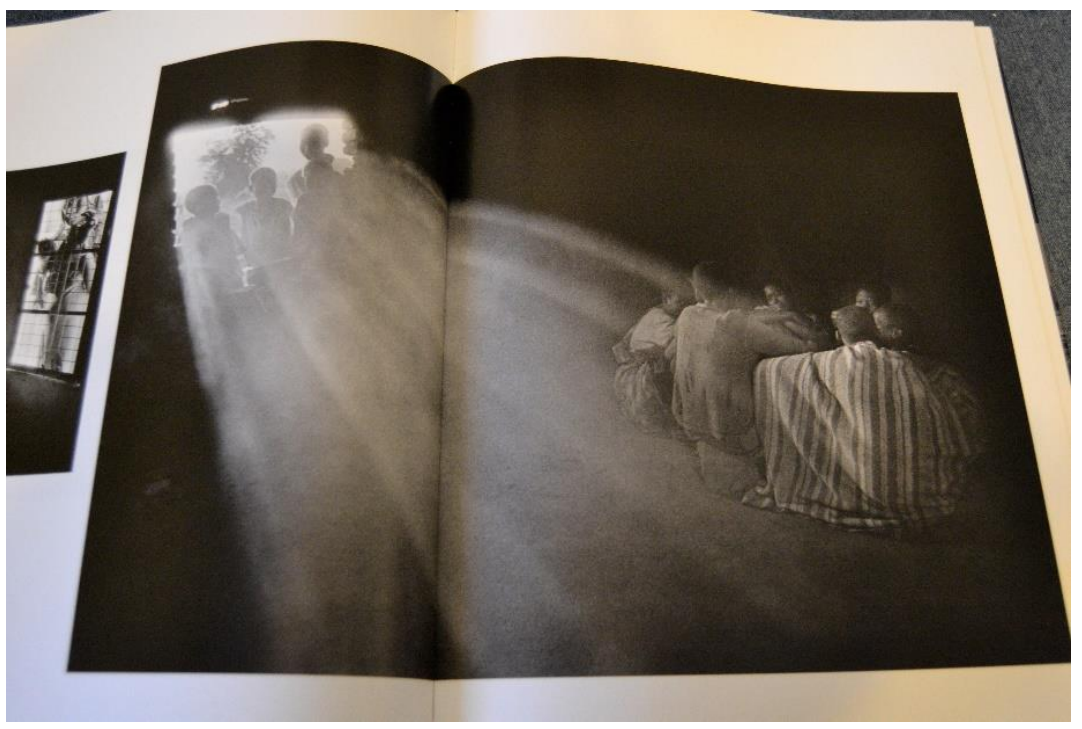

Imagem 6 


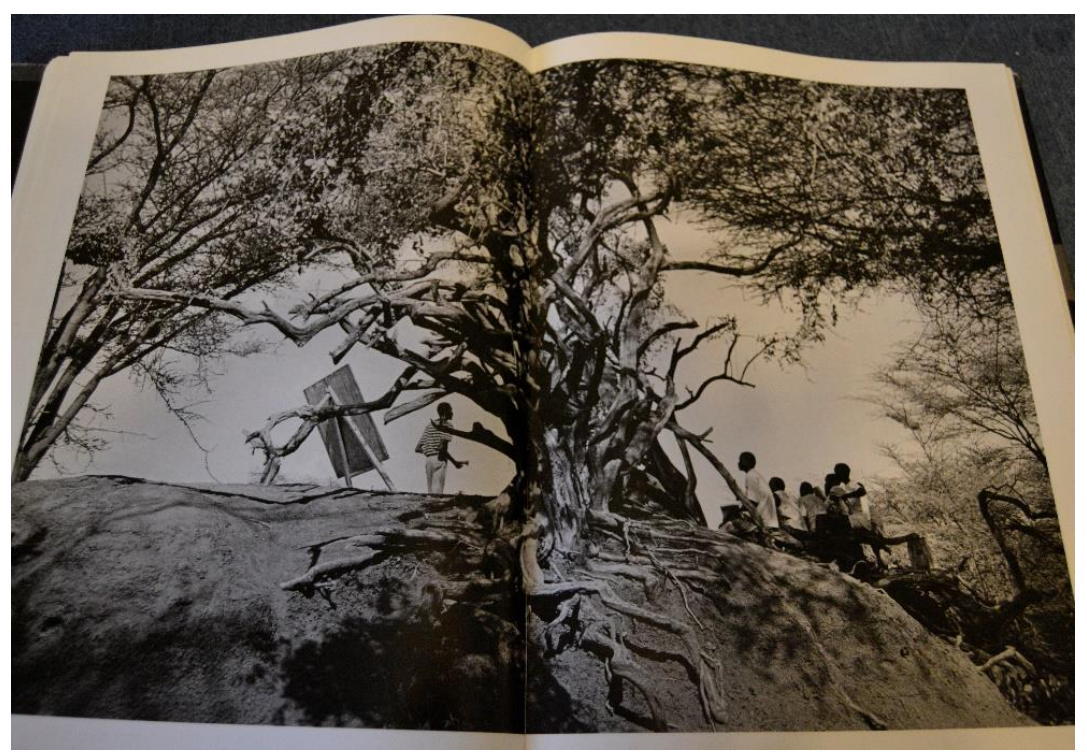

Imagem 7

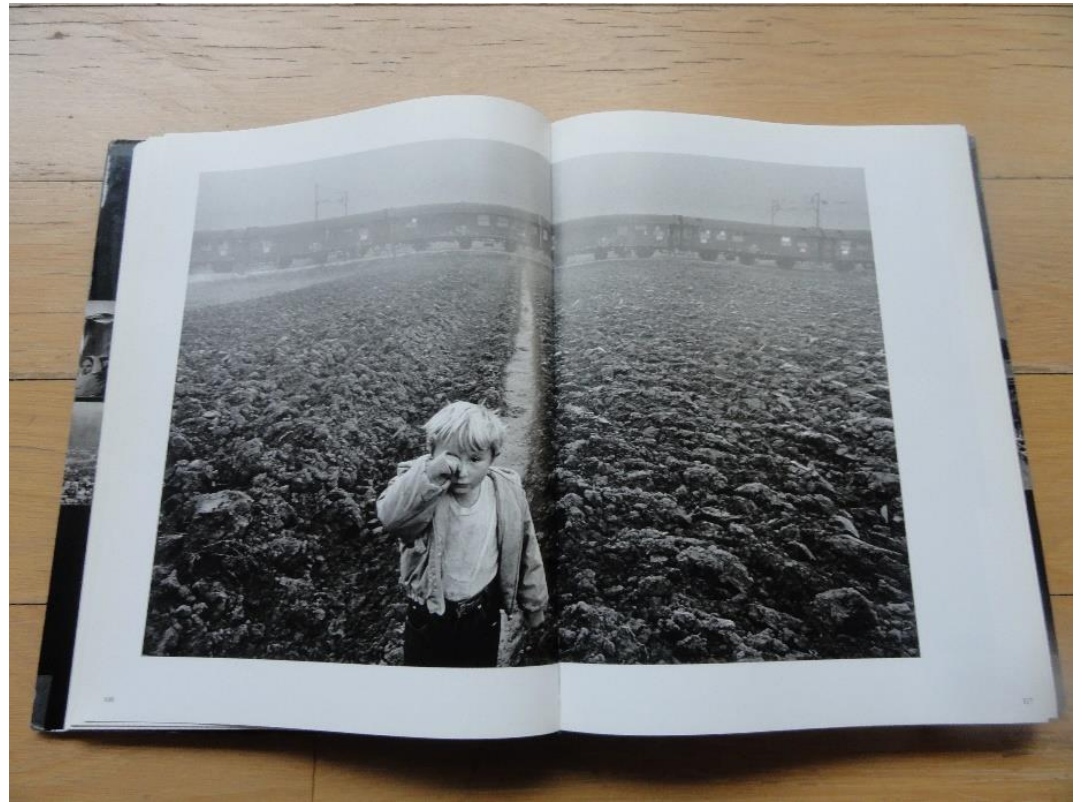

Imagem 8 


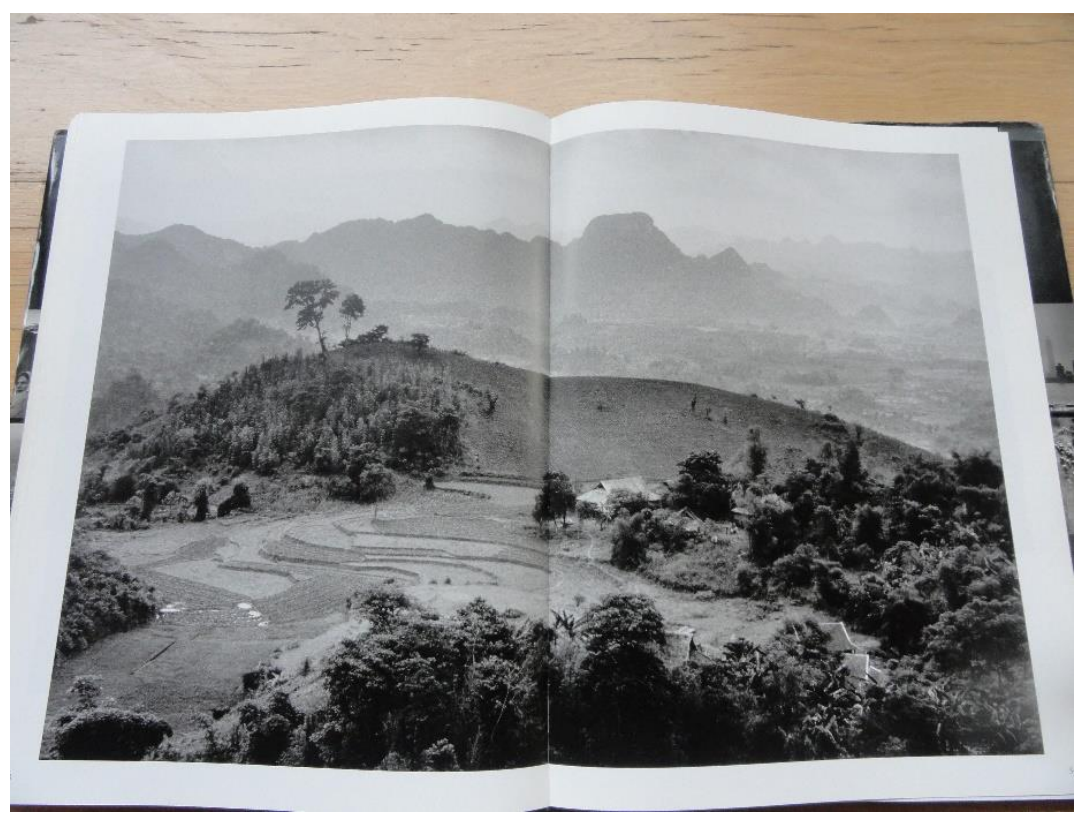

Imagem 9

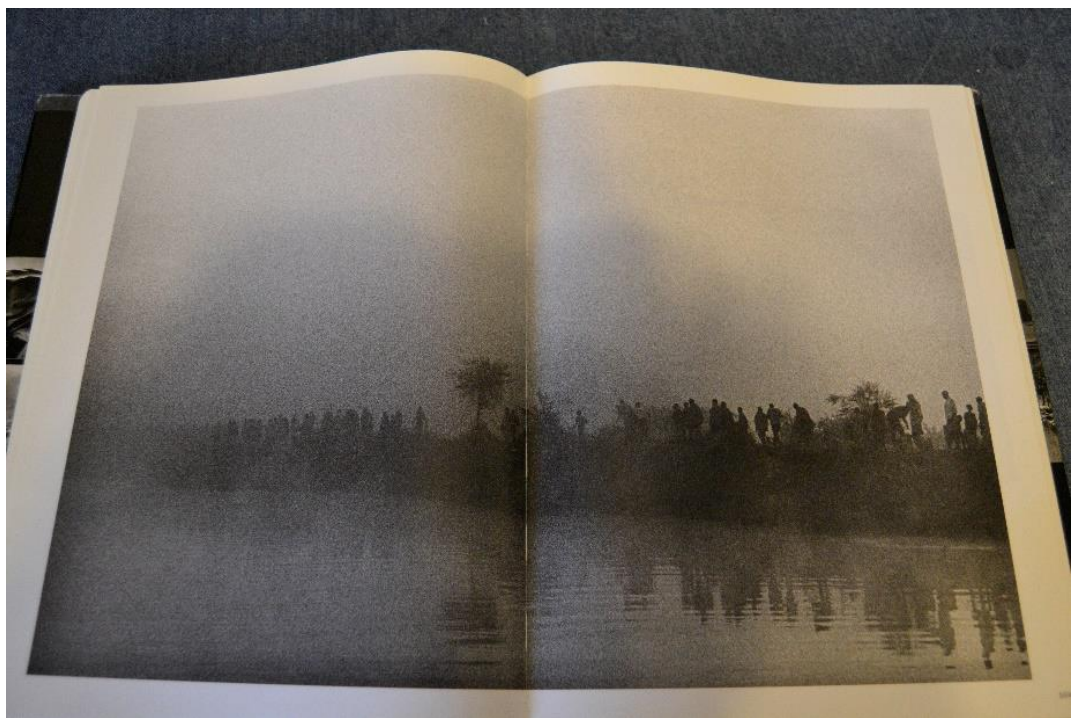

Imagem 10 


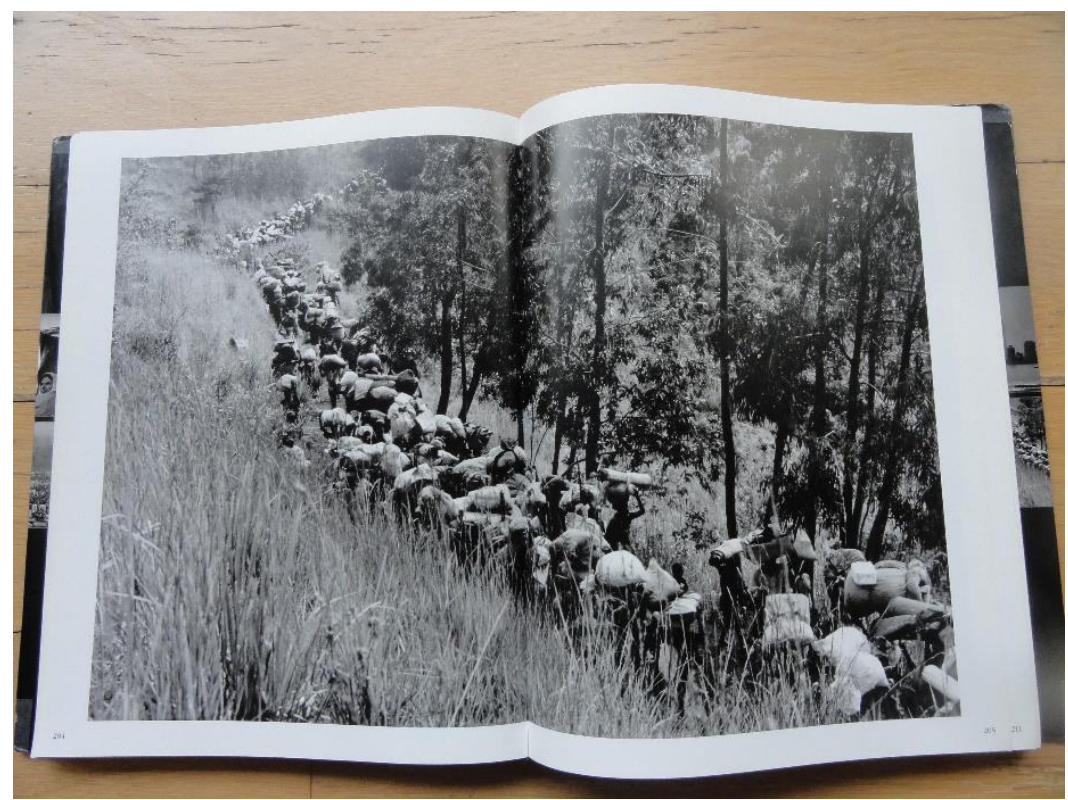

Imagem 11

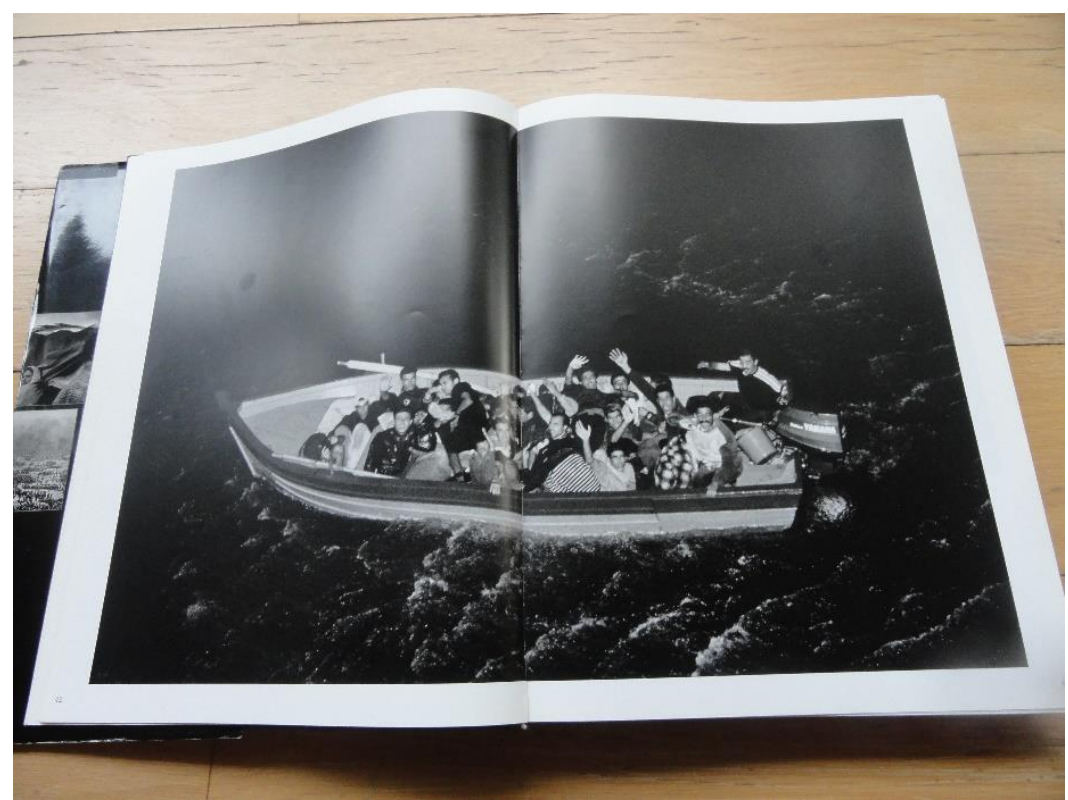

Imagem 12 


\section{NOTAS}

\footnotetext{
${ }^{1}$ Este artigo foi desenvolvido no âmbito da investigação realizada no Programa Estratégico Integrado
} UID/ELT/00500/2013 - POCI-01-0145-FEDER-007339.

2 Vide Benovsky, Jiri (2010).

${ }^{3}$ Vide http://www.amazonasimages.com/

${ }^{4}$ No quadro de uma irredutível defesa da autonomia da obra de arte moderna, é conhecido o sentido pejorativo atribuído pela teoria estética adorniana à “indústria cultural”. Mas não está agora aqui em discussão o modo como a fotografia, enquanto objeto de arte, se relaciona com a sociedade, mas tão só ou antes de mais, o impacto das novas tecnologias na produção, gestão e difusão das práticas artísticas e culturais.

${ }^{5}$ Se as fotografias não precisam propriamente de tradução e podem ser vistas em todo o lado (embora nunca da mesma maneira), o mesmo não acontece com o discurso verbal. Desde logo, com o título do álbum que, na versão inglesa - Migrations - surge despojado da sua evocação bíblica.

${ }^{6}$ Vide em anexo imagens 1 e 2 (in Salgado 2000: 22/23). Porque a fotografia, com em geral qualquer discurso semiótico, abarca o sentido que nela projecta aquele que é o observador num contexto preciso não completamente imune às circunstâncias de receção, reproduzo aqui as condições em que acedi às fotografias deste trabalho de Sebastião Salgado. As imagens que acompanham este texto dizem, por isso respeito, a algumas das páginas e fotografias da edição consultada do álbum Exodos.

7 Vide anexo imagem 3 (idem: 430-431)

${ }^{8}$ Vide em anexo imagem 4 (idem: 370/371)

9 Vide as suas frequentes colaborações com ONGs como Médecins sans Frontières, Cruz Vermelha ou Children's Fund.

10 Importará notar de que se trata aqui de uma exposição verbal a posteriori do seu percurso como fotógrafo...

11 Vide a propósito Benovsky 2010: 88.

12 Cf. Mora/Hill 1998.

13 Vide em anexo imagem 5 (idem: 246/247)

${ }^{14}$ Vide em anexo imagem 6, (idem: 155)

${ }^{15}$ Vide em anexo imagem 7 (idem: 164/165) 
16 Na realidade, segundo informação dada por Sebastião Salgado na respetiva legenda, trata-se de jovens sudaneses que fogem ao recrutamento do Exército no seu país em Guerra, e que num campo de refugiados no Quénia, em Kakuma, vão à escola possível.

17 Vide em anexo imagem 8 (idem: 116/117)

18 Vide em anexo imagem 9 (idem: 264/265)

${ }^{19}$ Vide em anexo imagem 10 (idem: 168/169).

20 "Os fotógrafos-testemunha podem pensar que é moralmente mais correcto tornar o espectacular não espectacular. Mas o espectacular é parte essencial das narrativas religiosas através das quais o sofrimento, ao longo da maior parte da história ocidental, tem sido entendido. E sentir o pulsar da iconografia cristã em certas fotografias de épocas de guerra ou de calamidades não é uma mera projecção sentimental." (Sontag 2003: 86)

${ }^{21}$ Filme realizado por Wim Wenders e por Juliano Ribeiro Salgado, filho de Sebastião Salgado.

${ }^{22}$ A propósito, vd. também o ensaio de Katherine Cheng (2006)

${ }^{23}$ Vide em anexo imagem 11 (idem: 204/205)

${ }^{24}$ Vide em anexo imagem 12 (idem: 42/43)

${ }^{25}$ Seja com retorno directo para o autor, seja para apoio de diferentes organizações humanitárias e, muito especialmente para o "Instituto Terra" , uma ONG fundada por Sebastião e Lélia Salgado em 1998, justamente no final da longa expedição a que o obrigou o projeto Êxodos. 0 Instituto surgiu com o objetivo primeiro de provocar uma «revolução verde» na terra natal do fotógrafo - Aimorés, Minas Gerais, o que foi sendo conseguido mediante uma extensa reflorestação da região com mata atlântica. Entretanto, em Novembro último, toda a região de Minas Gerais foi atingida por aquela que já é considerada a maior tragédia ambiental no Brasil, conhecido como o desastre da Mariana. O rompimento das barragens da Samarco causou um "tsunami" de lama e minério, destruindo todo o ecossistema da região. 0 "Instituto Terra", assim como Gênesis, o mais recente projeto fotográfico de Sebastião Salgado, foram patrocinados por uma das empresas que é dona da mineradora Samarco, aquela que precisamente causou esse enorme desastre ecológico. 0 "Comunicado sobre o Rio Doce", que se pode ler à entrada do site do "Instituto Terra", procura sobrepor-se à polémica entretanto gerada, reafirmando o seu compromisso de intervenção ecológica em todo o Vale do Rio Doce In http://www.institutoterra.org/pt br/\#.VrR32FKBaAN [última consulta em 20.01.2016]. 